\title{
Clinical Profile of Snake Bite Envenomation in Patients Admitted at Tertiary Care Hospital
}

\author{
N.Kotresh ${ }^{1}$, V.Sunitha ${ }^{2}$ \\ ${ }^{1}$ Associate Professor, Department of General Medicine, VIMS, Ballari, Karnataka, ${ }^{2}$ Resident, Department of General Medicine, VIMS, Ballari, Karnataka.
}

\section{Abstract}

Background: Snakebite envenoming is a potentially life-threatening disease that typically results from the injection of venom following the bite of a venomous snake. Sometimes envenoming can also be caused by venom being sprayed into a person's eyes by certain species of snakes that have the ability to spit venom as a defense measure. Not all snakebites are venomous. Some snakes are non-venomous and venomous snakes do not always inject venom during a bite. Subjects and Methods: Patients were examined for complications of snake bite. Haemotoxicity was assessed based on features like bleeding from the bite site, gums, epistaxis, haemoptysis, haematemesis, rectal bleeding or malaena, haematuria, vaginal bleeding, bleeding into the mucosae, skin (petechiae, purpura, discoid haemorrhages, ecchymoses. Neurotoxicity by drowsiness, paraesthesiae, abnormalities of taste and smell, ptosis, external ophthalmoplegia, paralysis of facial muscles and other muscles innervated by the cranial nerves, respiratory and generalized flaccid paralysis. Results: Majority of the patients were farmers with $44 \%$ followed by housewives (26\%). Lower limbs were the most common site of bite in our study group comprising of $74 \%$ of the patients. Conclusion: Most common manifestation of envenomation is local envenomation comprising of $66 \%$.

Keywords: Snake Bite Envenomation, Haemotoxicity, Neurotoxicity.

Corresponding Author: Dr. N. Kotresh, Associate Professor, Department of General Medicine, VIMS, Ballari, Karnataka.

Received: August 2019

Accepted: August 2019

\section{Introduction}

Snakebite is a predominantly rural problem mainly amongst farmers rampant in a tropical country like India. Most bites are inflicted on the feet and ankles of bare-footed agricultural workers who tread on snakes inadvertently while walking in the dark or working in fields and plantations. Snakebite is an occupational, environmental and domestic health hazard with a significant economic fallout on the individual and the family. ${ }^{[1]}$

The bites inflicted are frequently accidental as when snakes are trodden upon or could result due to sleeping on floor and open style habitation. The most affected region in the world is South East Asia because of dense population and extensive agricultural practices. Many of us worship snakes as gods and celebrate festivals like nagarapanchami in devotion. ${ }^{[2]}$

The WHO has included snake bite in its list of WHO neglected tropical diseases portfolio as a Category A neglected tropical disease in $2017^{[3]}$. It is time that WHO strictly implements its own policies for guideline development on snakebite envenoming in a transparent manner as is being done for other diseases. ${ }^{[4]}$

Snakebite envenoming is a potentially life-threatening disease that typically results from the injection of venom following the bite of a venomous snake. Sometimes envenoming can also be caused by venom being sprayed into a person's eyes by certain species of snakes that have the ability to spit venom as a defence measure. Not all snakebites are venomous. Some snakes are non-venomous and venomous snakes do not always inject venom during a bite. ${ }^{[5]}$ An accurate estimate for global morbidity and mortality of snake bite has been an uphill task due to various reasons. This is probably because of the prevalence of the disease among individuals in the poor agricultural and herding communities in low-and middle-income countries. They have limited options for health care and also have poor health education regarding the same. Due to poor socioeconomic background they resort to traditional methods of treatment which goes unnoticed by the official statistics. ${ }^{[5]}$

Most recent reveal a shocking data of a broad global estimate of 81,000 to $1,38,000$ deaths resulting from 1.8 million to 2.7 million cases of snakebite envenoming, and 4.5 to 5.4 million bites from venomous and non-venomous snakes. ${ }^{[6]}$ The recently released Global Burden of Disease 2016 study estimated that there was a total of 79,000 deaths caused by venomous animals in 2016. ${ }^{[7]}$

According to a National survey, the annual snakebite deaths nationally have been reported as 45,900. The highest rates have been reported in rural areas of India. It was seen that the state of Andhra Pradesh had the highest state rate for snake bite deaths $(6.2 / 100,000){ }^{[8]}$

The incidence and annual death rate in Karnataka is also $\mathrm{high}^{[8]}$ which is alarming as a good number of population is 
engaged in agricultural activities.

\section{Subjects and Methods}

Using purposive sampling technique, a minimum of 50 patients with history of snakebite was studied.

On admission, vital signs [pulse rate, respiratory rate, blood pressure, saturation of peripheral oxygen $(\mathrm{SpO} 2)]$, and site of bite was recorded.

Patients were examined for complications of snake bite. Haemotoxicity was assessed based on features like bleeding from the bite site, gums, epistaxis, haemoptysis, haematemesis, rectal bleeding or malaena, haematuria, vaginal bleeding, bleeding into the mucosae, skin (petechiae, purpura, discoid haemorrhages, ecchymoses. Neurotoxicity by drowsiness, paraesthesiae, abnormalities of taste and smell, ptosis, external ophthalmoplegia, paralysis of facial muscles and other muscles innervated by the cranial nerves, respiratory and generalised flaccid paralysis.

On patients presenting with history suggestive of snakebite, the following lab tests were included. Haemoglobin, TC (total count), DC (differential count), ESR (erythrocyte sedimentation rate), platelet count, PCV (packed cell volume), Peripheral smear, Urine routine and micro analysis, Serum CRP, LDH, APTT (activated partial thromboplastin time), PT-INR (prothrombin time with international normalized ratio). Serum CRP, $\mathrm{LDH}$ and $\mathrm{Hb}$ will be repeated later during the course of study when necessary.

\section{Inclusion Criteria}

- Patients with alleged history of snakebite.

- Patients with a history of unknown bite but with symptoms and signs compatible with snake bite envenomation.

\section{$\underline{\text { Exclusion Criteria }}$}

- Known case of any bite not caused by a snake.

- Patients with history of bleeding disorders

- Patients who received ASV before arriving to the hospital.

- Patient with a history of vasculitis

- Patient with a history of acute or chronic liver disease

- Patient with history of malignancy

- Patient with a history of acute myocardial infarction

\section{Results}

\begin{tabular}{|l|l|l|}
\hline Table 1: Age Distribution of the Patients \\
\hline Age in years & No. of patients & Percentage \\
\hline $18-30$ & 22 & $44 \%$ \\
\hline $31-40$ & 14 & $28 \%$ \\
\hline $41-50$ & 10 & $20 \%$ \\
\hline $51-60$ & 4 & $8 \%$ \\
\hline
\end{tabular}

Maximum incidence of snake bite occurred in the age group of 18 to 30 years $(44 \%)$.

The mean age of the patients was 35.22 years.
Table 2: Sex Distribution of Patients

\begin{tabular}{|l|l|}
\hline Male & Female \\
\hline 29 & 21 \\
\hline $58 \%$ & $42 \%$ \\
\hline
\end{tabular}

Majority were male with $58 \%$ and females with $42 \%$. The male to female ratio was $1.38: 1$.

Table 3: Occupational Profile of the Patients

\begin{tabular}{|l|l|l|}
\hline Occupation & Number of patients & Percentage \\
\hline Carpenter & 2 & $4 \%$ \\
\hline Labourer & 3 & $6 \%$ \\
\hline Driver & 2 & $4 \%$ \\
\hline Farmer & 22 & $44 \%$ \\
\hline Housewife & 13 & $26 \%$ \\
\hline Student & 7 & $14 \%$ \\
\hline Unemployed & 1 & $2 \%$ \\
\hline
\end{tabular}

Majority of the patients were farmers with $44 \%$ followed by housewives $(26 \%)$.

Table 4: Site of Snake Bite
\begin{tabular}{|l|l|l|}
\hline Site of the bite & Number & Percentage \\
\hline Right lower limb & 18 & $36 \%$ \\
\hline Left lower limb & 19 & $38 \%$ \\
\hline Right upper limb & 5 & $10 \%$ \\
\hline Left upper limb & 3 & $6 \%$ \\
\hline Miscellaneous & 5 & $10 \%$ \\
\hline Total & 50 & \\
\hline
\end{tabular}

Lower limbs were the most common site of bite in our study group comprising of $74 \%$ of the patients.

Table 5: Manifestations of Envenomation

\begin{tabular}{|l|l|l|}
\hline Manifestation of envenomation & No. of patients & Percentage \\
\hline Haemotoxic & 15 & $30 \%$ \\
\hline Neurotoxic & 10 & $20 \%$ \\
\hline Local & 33 & $66 \%$ \\
\hline
\end{tabular}

Most common manifestation of envenomation is local envenomation comprising of $66 \%$.

\section{Discussion}

Majority of snakebite patients in this part of the country present with haemotoxic envenomation and its complications. While very few studies have been done demonstrating the role of serum LDH as a marker of haemolysis and CRP of acute inflammatory response, there have been no significant studies done showing a correlation between $\mathrm{Hb}$ and haemotoxicity in snakebite victims. Hence in this study we aimed to analyze the relationship between serum CRP, LDH and $\mathrm{Hb}$ with haematological profile, and to ascertain their utility as markers of haemotoxicity in snakebite victims.

This study showed that the occurrence of snakebite was higher in the working age group. Maximum incidence of snake bite occurred in the age group of 18 to 30 years. The 
mean age of the patients was 35.22 years. This correlated with other studies done by Suchithra N, et al., Monteiro FN, et al and Sharma SK, et al. where the mean age was $40,40.7$ and 32 years respectively. As most patients affected fall in the working age group it places a great economic burden on the family and caused an impact on socioeconomic status.

In the present study the incidence of snakebite was seen to be higher in males (58\%) compared to females $(42 \%)$ and the ratio being $1.38: 1$. The higher incidence in males might be attributed to higher exposure of males to outdoor environment and farming and hence the risk of snakebite. This was in correlation with other studies like the one by Monteiro FN, et al. ${ }^{[9]}$ where the ratio was $1.38: 1$ and by Kulkarni ML, et al. ${ }^{[10]}$ where the ratio was 2.17:1.

Snake bites were commonly seen among agricultural workers in the present study with 22 patients being farmers (44\%). Next more commonly it was seen housewives (26\%). Similar findings have been reported in a study done by Dayananda et $\mathrm{al}^{[11]}$, where $73 \%$ of the population was found to be engaged in agricultural activities and was also seen in a epidemiological study done by Bawaskar et al. In another study done by D P Punde ${ }^{[12]}$, similar findings were found where farmers were affected the most (36\%).

In our study lower limb were the commonest sites of snakebite. The ratio of lower limb to upper limb bites was 2.84:1. A study done by Saravu K, et al. ${ }^{[13]}$ showed a ratio of 3.48:1. Another study done by David S, et al. ${ }^{[14]}$ showed that lower limb bites were 3.44 times more common than those of upper limb bites. As most of these bites happen outdoors especially either at night on accidental stepping or while working in the fields, lower limbs tend to have higher incidence of bite site than upper limb. Upper limb bites or bites on other parts of the body usually occur in patients during sleep.

In the present study, haemotoxic envenomation with coagulopathy was higher in occurrence compared to neurotoxic envenomation. A Study done by DP Punde ${ }^{[12]}$, showed a similar result of $64.2 \%$ of the victims developing coagulopathy after snakebite due to Echiscarinatus. This was also in correlation with a study done by Kulkarni ML, et al. ${ }^{[10]}$ at Davangere which showed a similar result with $58.6 \%$ patients developing coagulopathy after snakebite. A study done by Suchithra N, et al. ${ }^{[15]}$ in Kerala showed $71 \%$ of patients demonstrating coagulopathy after snakebite. These results could be seen as a consequence of increased number of viper bites rather than elapid bites in the respective regions.

\section{Conclusion}

- Maximum incidence of snake bite occurred in the age group of 18 to 30 years. The mean age of the patients was 35.22 years.

- Majority were male with 58\% and females with $42 \%$ with male to female ratio is $1.38: 1$.

- Majority of the patients were farmers with $44 \%$ followed by housewives (26\%).

- Lower limbs were the most common site of bite in our study group comprising of $74 \%$.

- Most common manifestation of envenomation is local envenomation comprising of $66 \%$.

\section{References}

1. Warrell DA (1995) Clinical toxicology of Snake bites in Asia. In: White MA, ed. Handbook of clinical toxicology of animal venoms and poisons CRC Press. p 493-588.

2. Whitaker R, Captain A (2004) Snakes of India, the field guide. Chengalpattu, India: Draco Books. 483 p.

3. Khan MS (2002) A guide to the snakes of Pakistan. Frankfurt am Main, Germany: Chimaira. 265 p.

4. Shah KB, Tiwari S (2004) Herpetofauna of Nepal - a conservation companion. Kathmandu, Nepal: The World Conservation Union. $237 \mathrm{p}$.

5. Ahmed SM,Nadeem A, Islam MS, Agarwal S, Singh L. Retrospective analysis of snake victims in Northern India admitted in a tertiary level institute. J AnaesthesiolClinPharmacol 2012; 28:45-50.

6. Parekh Ck. Text Book Of Forensic Medicine And Toxicology, Jaypee Brothers 2000; 9:41-4

7. DeorasPj. Snakes Of India; 4TH Ed (Revised), National Book Trust, India 1999: 65-70.

8. Ahmed SM, Ahmed M, Nadeem A, Mahajan J, Choudhary A, Pal J. Emergency treatment of a snake bite: Pearls from literature. J Emerg Trauma Shock. 2008 Jul;1(2):97-105.

9. Monteiro FN, Kanchan T, Bhagavath P, Kumar GP, Menezes RG, Yoganarasimha K. Clinico-epidemiological features of viper bite envenomation: a study from Manipal, South India. Singapore Med J. 2012; 53:203-7.

10. Kulkarni ML, Anees S. Snake venom poisoning: experience with 633 cases. Indian Pediatrics. 1994 Oct 31; 1:1239-43.

11. Dayananda KS, Reddy PJ, Raju EV, Babu TH. Epidemiological Study of Snakebite Cases Admitted in Victoria Hospital, Bangalore. International Journal of Medicine and Medical Sciences. 2013;46(3):1304.

12. Punde DP. Management of snakebite in rural Maharashtra: A $10 \mathrm{yr}$ Experience, The National Medical Journal of India. 2005 Mar 1;18(2):71.

13. Saravu K, Somavarapu V, Shastry AB, Kumar R. Clinical profile, species-specific severity grading, and outcome determinants of snake envenomation: An Indian tertiary care hospital-based prospective study. Indian Journal of critical care medicine. 2012 Oct;16(4):187.

14. David S, Matathia S, Christopher S. Mortality predictors of snake bite envenomation in southern India-a ten-year retrospective audit of 533 patients.Journal of medical toxicology. 2012 Jun 1;8(2):11823.

15. Suchithra N, Pappachan JM, Sujathan P. Snakebite envenoming in Kerala, South India: clinical profile and factors involved in adverse outcomes. Emergency Medicine Journal. 2008 Apr 1;25(4):200-4.

Copyright: (C) the author(s), 2019. It is an open-access article distributed under the terms of the Creative Commons Attribution License (CC BY 4.0), which permits authors to retain ownership of the copyright for their content, and allow anyone to download, reuse, reprint, modify, distribute and/or copy the content as long as the original authors and source are cited.

How to cite this article: Kotresh N, Sunitha V. Clinical Profile of Snake Bite Envenomation in Patients Admitted at Tertiary Care Hospital. Acad. J Med. 2019; 2(2):5-7.

DOI: dx.doi.org/10.21276/ajm.2019.2.2.2

Source of Support: Nil, Conflict of Interest: None declared. 